\title{
Mesenteric Artery
}

National Cancer Institute

\section{Source}

National Cancer Institute. Mesenteric Artery. NCI Thesaurus. Code C52975.

A branch of the abdominal aorta that supplies blood to the intestines. 